\title{
Electricity, Heat and Gas Marketing Information System Based on SOA Architecture
}

\author{
Zhigang $\mathrm{Li}^{1,2,3}$, Dongqing Zhu' ${ }^{3}$, Quan $\mathrm{Qi}^{3}$ \\ 1. College of Economics \& Management, China \\ Agricultural University, Beijing ,100083, China \\ 2. Xinjiang TianFu Thermoelectric CO., LTD, Shihezi \\ City, 832000, Xinjiang, China \\ 3. Collage of Information Science and Technology, \\ Shihezi University, Shihezi City, 832000,Xinjiang, \\ China \\ E-mail:lzg_inf@shzu.edu.cn
}

\author{
Zetian Fu \\ College of Economics \& Management, China \\ Agricultural University, Beijing ,100083, China \\ Jiayong He \\ Xinjiang TianFu Thermoelectric CO., LTD, Shihezi \\ City, 832000, Xinjiang, China \\ E-mail:lzg_inf@shzu.edu.cn
}

\begin{abstract}
Power marketing in the United States, Europe, Japan and other developed countries has entered the era of intelligent and networked. Domestic power marketing system means more backward, and the marketing organization system is imperfect. With the intensified competition of market, the Tianfu Thermoelectric original marketing information systems cannot satisfy the development needs of the enterprise, which lacks of top-down overall informatization construction planning and scattered IC cards. According to the current operating status of the joint stock company and existing problems, the establishment of an integrated marketing platform with electricity, heat and gas business is built on a unified infrastructure platform in order to unify customer information, marketing basic platform capabilities and customer service platform function, centralize management of electricity, heat, gas marketing business in one of a big marketing intensive management mode including electricity, heat and gas.
\end{abstract}

Keywords- SOA Architecture; Marketing Information System; J2EE; Integration)

\section{INTRODUCTION}

\section{A. Development status at home and abroad}

The State Grid Corporation proposed the "SG186 Project" plan of system-wide implementation in April 29, 2006,. According to the plan, "SG186 project" will achieve four goals: the first one is to build "longitudinal through, transverse integration" platform, to achieve information and data sharing in companies; the second one is to build eight business applications to adapt to the company's management needs and improve the ability of management of business in the company; the third one is to establish and perfect six information guarantee systems, to promote the rapid, healthy and sustainable development of informatization; and the last one is to the goal of be domestic and international advanced by the end of "eleventh five-year plan", initially set up digital power grid and informationization enterprise[1].

Status of abroad electricity marketing: At present, power marketing in the United States, Europe, Japan and other developed countries has entered the era of intelligent and networked. The traditional marketing content of recording, counting and charging, has changed to a new work system of customer-centered, purpose-promoting and service-aim. Customer's payment is flexible, including e-banking network, cash and check by weekly, fortnightly, monthly and quarterly, or long-term orders and payment cards[2][3][4]. Looked from the overall, developed foreign power supply enterprise in the electric power market after deregulation pay more attention to intelligence technology and equipment adopted, improve the reliability and quality of power supply, more ability to focus on customer service, make full use of automatic meter reading, intelligent ammeter, network technology, call center technology and Internet technology, make the response service faster and better[5].

The status of domestic electricity marketing: 1) Reform and adjust marketing institution. At present, the reform and adjustment are moving to adapt to the development of market economy and the direction of the new situation of the electricity buyer's market. 2) Adoption of new technical means. With the rapid development of computer and network communication technology, the new technology used in power marketing is growing, multi-purpose time-sharing power meter and automatic meter reading technology in data acquisition and transmission are widely used. 3) A large amount power customer service center emerges. The establishment of the customer service center makes the electric power enterprises more standardized and modernized for customer services, both service quality and efficiency of services develop quickly, and service is significantly improved[6][7][8][9].

\section{B. Problems in domestic power marketing}

- Backward in technology. Due to the lack of longterm investment and fixed funding channels, equipment and overall marketing means are still relatively backward, and cannot satisfy the needs of the present.

- Imperfect marketing organization system. The entire power enterprises did not realize market is guidance and economic benefit is center. The marketing department failed to intervene in the power balance of resources and electricity price 
estimates, lacked enough electricity market depth research and forecasting analysis, which led to ineffective measures to open up the market.

- Information coding unrealized standardization. Marketing system at all levels of the construction and application "each does things in his own way". Types of complex equipment, network architecture, software and hardware platforms, the choice of different database, function setting and classification of disunity, business processing and work flow is not standard, the application level is uneven. Most of the systems have no management decision function.

- Low quality of personnel cannot satisfy the needs of modern marketing. The existing marketing staff is planned economy and power shortage period, facing the new situation, here is a widespread technology service quality is low and ideas behind problems.

\section{Development trend of domestic electric power marketing}

Throughout the path of development of large enterprises at home and abroad and the prevailing information development model, regardless of the scale of enterprises, the extent of the number of branches in the world, enterprises require building a unified business information platform covering the entire enterprise business and the department of business, for the entire enterprise information system operation to provide basic conditions, ensure that the centralization and integration of information construction.

Power enterprise information construction planning and development goals, according to the principle of "four unified" must be implemented from the top down, the unified leadership, unified planning, unified standards, unified organization implementation, in accordance with the design of the overall planning, step-by-step implementation, pilot promotion, strong propulsion way concrete implementation. Enterprise application system at all levels to achieve integration and integration, while further standardize business processes realizing the optimized management and process reorganization, through the information construction, to promote the establishment of new modern enterprise system in power enterprise.

\section{The current situation of the development of information in Xinjiang Tianfu Thermoelectric Co., LTD.}

Xinjiang Tianfu Thermoelectric Company was established in March 1999, is mainly engaged in the production and supply of electricity, heat and gas. The company is the only one in Xinjiang co-generation, combined heat and power generation, Fire and water electricity, generate ,offer, adjustable integrated electric energy enterprise. Up to now, the company has more than 5000 employees, the total assets of 7.3 billion RMB Yuan, with a total installed capacity of $437 \mathrm{mw}$ power, supply nearly 2 billion kilowatt hour, heating load 10.86 million GJ, power generation capacity and coal production capacity in the corps. The company now has six Wholly-owned branch and 14 share subsidiaries.
After the continuous information construction in the past few years, has built a power marketing management information systems, the rural power marketing management information systems, heating marketing management information systems and a number of excellent marketing information system, for marketing services provide excellent information technology support, has played an invaluable role in the survival and development of enterprises.

In recent years, with the continuous development of the electricity market, In order to deal with the fierce market competition, and Tianfu Thermoelectric significantly expand the installed capacity, greatly enhancing the market competitiveness of enterprises. But we also see that there are a lot of inadequacies. Mainly include: The market competition intensifies; The original marketing information system can't meet the development needs of the enterprise; The lack of top-down whole informatization construction planning; IC card is not uniform.

According to the joint stock company current operating status and existing problems, it is necessary to establish an integrated big marketing platform, electricity, heat, gas business is built on a unified platform on top of the foundation, unified customer information, marketing basic platform capabilities and customer service platform function, electricity, heat, gas marketing business centralized and unified management, Achieve electricity, heat, gas in integrated big marketing intensive management mode, to provide customers with one-stop service, enhance the core competitiveness of enterprises, improve the capacity and quality of customer service.

\section{THE DESIGN IDEA OF SySTEM}

The Tianfu heat, electricity, gas marketing and management information systems is not a replica of the manual work, more than with the advanced computer technology to packaging the existing management mode, but integration into some advanced management ideas and the latest marketing research, such as the CRM (Customer Relationship Management),ERP(Enterprise Resource Planning), BPR(Business Process Reengineer) and ISO9000 certification system, to realize the service innovation, management innovation and technology innovation.

- Streamline jobs ideological. Through a variety of enterprise resource planning, daily management, internal work coordination, industry norms, electricity customers and electric energy market requirements and other aspects of business activity analysis, abstraction, generalization, abstracting the transaction unit, then a number of transaction processing unit according to a certain logic in-line process, business processing in wizard mode.

- Flat management. Customer service, marketing business restructuring, and break the professional fragmented, reduce intermediate links, and improve process speed of operation and information sharing of resources between the various departments and posts. Customer service as the core, restructuring of marketing business, and break the professional fragmented, reduce intermediate links, to improve 
the speed of process operation and achieved the sharing of information resources between the various departments and posts. To build the integrated marketing system of Tianfu Thermoelectric as this structure of the pyramid, quick response, represent and safeguard the interests of customers, so that the marketing efficiency maximization.

- Optimal management of resources. Including: information resources integration and sharing; data resources integration; business resource integration; business hall resource integration; equipment resource integration; human resource integration.

\section{SOA-ORIENTED PlATFORM ARCHITECTURE}

Service-Oriented Architecture (SOA) is a component model. Using open standard makes the different functional units of application (known as Service) through the interfaces and the bonds linked together, the key is to realize the business application integration and components reuse by other system[10].Most fundamental characteristics of SOA are to solve the difficult problem of interaction between some systems. It makes the business logic of the application or some single function modular as a service, presented to the client. In the service-oriented architecture, each service has been designed to be functional elements of themeoriented tasks, at the same time as a part of the entire system processes to call other services. Around the service all patterns are based on the standard technology, therefore, SOA can be applied to any existing system and to avoid the integrated process of dependence to follow any special custom. SOA need not be limited to a certain technology or development language to realize, at this stage, there are many SOA technologies, and the most mature, the most convenient technical realization is Web Service[11].

In the study of electricity, heat, gas marketing and management information system on the basis of the actual demand in open, standard, integrated. To research based on a service-oriented architecture (SOA) integration of marketing and management information systems. Utilized the business components, services and applications layered design idea, studies on electrical, heat, gas marketing system involving key technology such as the Java EE technology, XML technology, Web application framework, workflow service, rights management services, integration services, gallery electric gas fee calculation service, charging management services, statements of management services and so on. As shown in Figure 1.

\section{IV. BUSINESS PROCESSES OF INTEGRATED MARKETING INFORMATION SYSTEM PLATFORM}

Marketing and management information systems business process is shown in Figure 2.

\section{A. Business expansion process analysis}

Business expansion process design based on: customer's business services are convenient and fast, customer's application, fee and signing the contract, both are realized in the business hall, Truly realized that "one window to customers, business turns inside not circulation at outside". For internal according to power supply business standardization requirements, to ensure that each department responsibilities, boundaries clear, business norms, makes the business expansion reported and installation process work achieve efficient at internal operation, quality service to the grand number of electricity customers, to achieve maximum power efficiency of the power system. Business expansion reported and installation process overall workflow was shown in Figure 3.

\section{B. Charges business process analysis}

Meter reading, audit and charges business process flow diagram as shown in Figure 4.

C. Analysis of the measurement business process

Periodic verification and on-site check flowchart (shown in Figure 5).

\section{DESIGN AND IMPLEMENTATION OF INTEGRATED MARKETING INFORMATION SYSTEM}

\section{A. Basic idea of the system design}

Tianfu actual electricity demand oriented, design the framework of the overall structure of the marketing system, and studies the key technologies.

- Gathering of domestic and international the electricity enterprise marketing information system technology information, the analysis of the current Tianfu thermoelectric electricity, heat, gas business marketing system functions, Grasp the key technology for analysis and design of SOA.

- According to the actual needs of Tianfu Thermoelectric and the existing basis for the work of the subject $\mathrm{R} \& \mathrm{D}$ units, depth Tianfu Thermoelectric departments, research in production and management, business process, infrastructure and other specific needs, according to the difference of electricity, heat and gas business information classification.

- According to the results of research, in the overall framework of the marketing system is designed on the basis of the existing system of electricity, heat, gas, carry out the overall design of the system program.

- Invited power experts and related areas of information technology expert analysis and appraisal of the joint system program, and according to the result of argument further research and revised design scheme.

- Raised the overall system architecture design scheme. Firstly gives the design goals and design principles of the system, and then describe the business and functional architecture of the system, the system's technical architecture, and discusses in detail the architecture of the J2EE three-tier B/A/S, SOA, related technical data warehouse system. 


\section{B. System design research methods}

- According to the electricity, heat, gas market information, business information is different, classification, integrated design.

- Establish the appropriate options for different type of customer, the type of service and the type of management, development and design the corresponding functional options, automatic user the type recognition technology, the development of a data acquisition system.

- Technically using SOA, J2EE three-tier B/A/S architecture, data warehouse technology.

\section{The basic content of the system design}

\section{1) Analysis and design of SOA}

Marketing technical support system using a SOA for application design, development, systems integration, be able to get rid of the shackles of technology-oriented solutions, concentrate on building the fields of electricity, heat, gas marketing business model, so as to improve software reuse, accelerate the implementation of software.

\section{2) Building J2EE three-tier B/A /S architecture}

J2EE is a use of Java platform to simplify the development of enterprise solutions, deploy and manage complex issues related to the system architecture is a component-based architecture.

3) Design of the data warehouse system

The data warehouse application architecture is composed by the transaction processing environment, online analytical environment and the front-end display tools composition, to build user business expanding installed management subsystems, electric heat metering and billing management, customer service, system management systems and so on.

\section{System function framework}

System function framework shown in Figure 6.

1) Business Expanding functional modules

Mainly includes:1.Parameter settings.2. Work order processin. 3.Management of business expansion costs. 4 . Contract Management(Main processing contract category maintenance, customer power supply contract entry, etc.)5.Customer Information inquiry.6. Business inquiries. 7. Statistical form. Shown in Figure 7.

2) Charges functional modules

Subscription management subsystem core work is to establish a set of customers electricity Archives and receivable file, According to subsystems and measurement business expanding subsystem provides the basic data to accurate, timely calculate electricity file and generate receivable records, at the same time in electricity file to reflect changes in customer profiles and metering devices.

\section{3) Metering function module}

Electric energy measurement management system tracking and management of all energy metering equipment assets file, configured for each metering point equipment, and arrange for a variety of cycle rotation check program, calculate the error of each measurement point metering device, along with a variety of query functions, automatically generate various reports. The measurement management subsystem is divided into the following several subsystem: Energy meter management, transformer management, standard equipment and indicating instrument management, work order processing, external test management, statistical reports management, fault handling, measuring personnel and document management, and so on.

4) Electricity, heat, gas, IC card "One-Card" system

Intelligent card type electric energy meter and the overall promotion will realize meter, charging, control of the Trinity; fundamentally eliminate defaults charge of electricity phenomenon. At the same time to change the long-standing "pay after use" settlement mode, achieved "first pay then use electricity". Compared with ordinary electric energy meter, smart card meter has a capacity meter, electricity more secure, have to remind function, payment to facilitate the purchase of electricity, with automatic meter reading function, and enables the user consumption as clear as noonday. In order to unify the management, the convenience of users, we must construct electricity, heat, gas uniform IC card application platform, implementation of "one card ", completely solve the problem of compatibility of intelligent card. The enterprise management difficulty is reduced to the minimum, the user only one card can realize the electrical, thermal, gas fee business.

5) Marketing analysis and auxiliary decision system

Marketing analysis and auxiliary decision system based on "the data concentration, applied concentrated" integrated marketing information system platform as the foundation, building high-end applications in the data center of the group, with electricity, heat, gas and other various subordinate enterprises of marketing related business data as the foundation, relying on each subordinate enterprise's database to build marketing assisted decision-making analysis center data warehouse, to achieve online analytical processing, marketing assisted decision-making analysis work of digitization management.

Through the integration platform of the data exchange platform to realize each business system marketing data longitudinal through. Systems using data warehouse technology and business intelligence tools, a comprehensive analysis of operating data and other relevant information and depth of mining, achieve market operation, marketing ability, customer service and equipment assets and other types of analysis and forecast of the theme. Through data analysis and mining, provide auxiliary decision support for power production and operation process, provide electricity marketing analysis, business expanding analysis, analysis of metering device analysis, electrical examination analysis, large user analysis and statistical analysis, regulatory analysis and intelligent inquiry.

\section{CONCLUSION}

The system uses a service-oriented architecture (SOA), J2EE three-tier B / A / S system and the data warehouse technology. According to the latest electric, gas, fuel gas and other individual marketing management system research, application of service oriented architecture (SOA) 
framework system, fast and efficient, time-saving and laborsaving, low integration of enterprise information system single, meet the strategic goal of the enterprise demand, construction has the core competitiveness of the enterprise information system.

\section{ACKNOWLEDGMENT}

This project was supported by Postdoctoral Funded Projects Fund: Research of Electricity, Heat, Gas Smart IC card Platform Marketing Management Information System of Xinjiang TianFu Thermoelectric CO., LTD.

\section{REFERENCES}

[1]. State Grid Corporation of China $<$ Marketing and management of business applications overall construction program $>2006,6$.

[2]. XU Weiting,LIU Junyong,LIU Youbo,HU Can.Summary of research on intelligent sales and marketing of smart grid (1): current situation of relevant research abroad and revelation[J]. Electric Power Automation Equipment. Feb. 2010.Vol. 30 No. 2:139-144

[3]. Nie Yun Shen, He Xue Ming. France, Japan, the United States electric power marketing mode overview. State Grid.2007.8

[4]. XU Jie-yan,MI Xin-ping. Analysis of power marketing in Japan[J]. Power Demand Side Management,2012.03

[5]. Hong Tao. The business design of the marketing technical support system of the Shan dong Electric Power[D]. North China Electric Power University(He Bei),2008

[6]. Shandong Electric Power Group Corporation.County-powered corporate power marketing technical support system functional technical specifications[S].2006.

[7]. Qiu Xianhui.The construction of the power marketing system[J].Guangxi Electric,2007,4.

[8]. Zhou Wenyu,Wang Tao,Shen Youxing.Research and Development of the electricity marketing decision support system[J].Power System Technology,2006,30(supplement):540-544.

[9]. Wang Fei,Lu Jianjun,Zheng Wenyan.Research and Application of Struts in J2EE Web layer[M].Modern electronic technology,2006,29(18):68-70.

[10]. Panagiotis Louridas.SOAP and Web Services[J].Software,IEEE,2006,23(6).

[11]. Huan Changwu,Li Rui,Wang Jianlin.Design and Implementation of the power marketing system based on J2EE technology and SOA architecture[J].Computer and Information Technology,2006,11.

\begin{tabular}{|c|c|c|c|c|c|c|c|}
\hline Presentation layer & \multicolumn{7}{|c|}{ Industry expanding, measurement, dosage fees, charges, inspection, etc. Used in each module interface display } \\
\hline Business Logic Layer & \multicolumn{7}{|c|}{ Realization of business logic (business components, services), external interface, service calls, etc. } \\
\hline $\begin{array}{l}\text { Application } \\
\text { services layer }\end{array}$ & $\begin{array}{c}\text { Web } \\
\text { application } \\
\text { framework }\end{array}$ & $\begin{array}{c}\text { Workflow } \\
\text { Services }\end{array}$ & $\begin{array}{c}\text { Rights } \\
\text { Management } \\
\text { Services }\end{array}$ & $\begin{array}{c}\text { The } \\
\text { Gallery } \\
\text { integration } \\
\text { of service }\end{array}$ & $\begin{array}{c}\text { Cost } \\
\text { computing } \\
\text { services }\end{array}$ & $\begin{array}{l}\text { Fee management } \\
\text { services }\end{array}$ & $\begin{array}{c}\text { Report management } \\
\text { services }\end{array}$ \\
\hline Persistence layer & \multicolumn{7}{|c|}{ Data access, data objects } \\
\hline $\begin{array}{l}\text { J2EE infrastructure } \\
\text { services layer }\end{array}$ & \multicolumn{7}{|c|}{ Enterprise Application Server: J2EE API (such as JNDI, JDBC, JTA, JMS, etc.) } \\
\hline System resources layer & \multicolumn{7}{|c|}{ Database management systems, network protocols, operating systems } \\
\hline
\end{tabular}

Figure 1. Platform Architecture Figure 


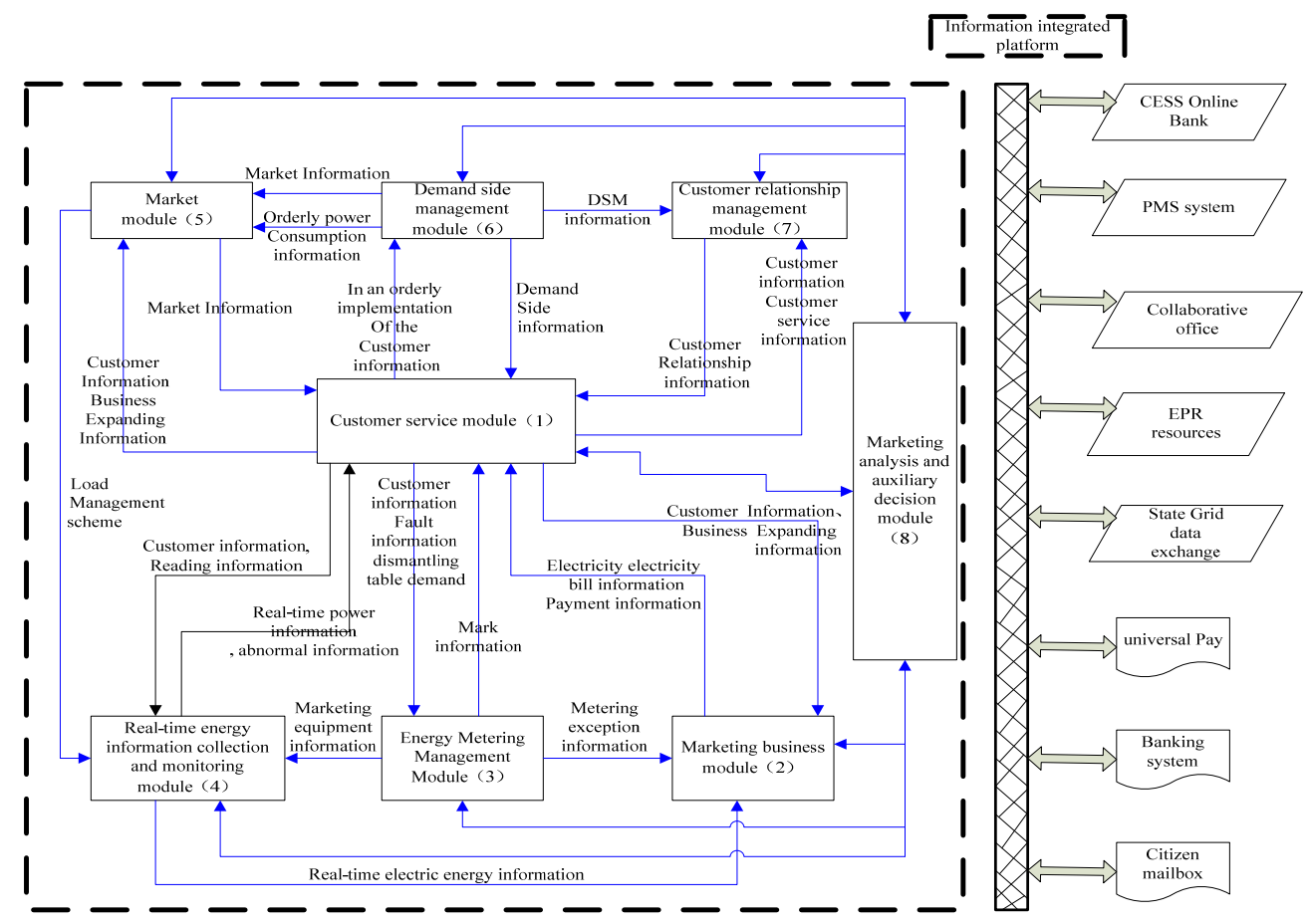

Figure 2. Marketing and management information systems business processes

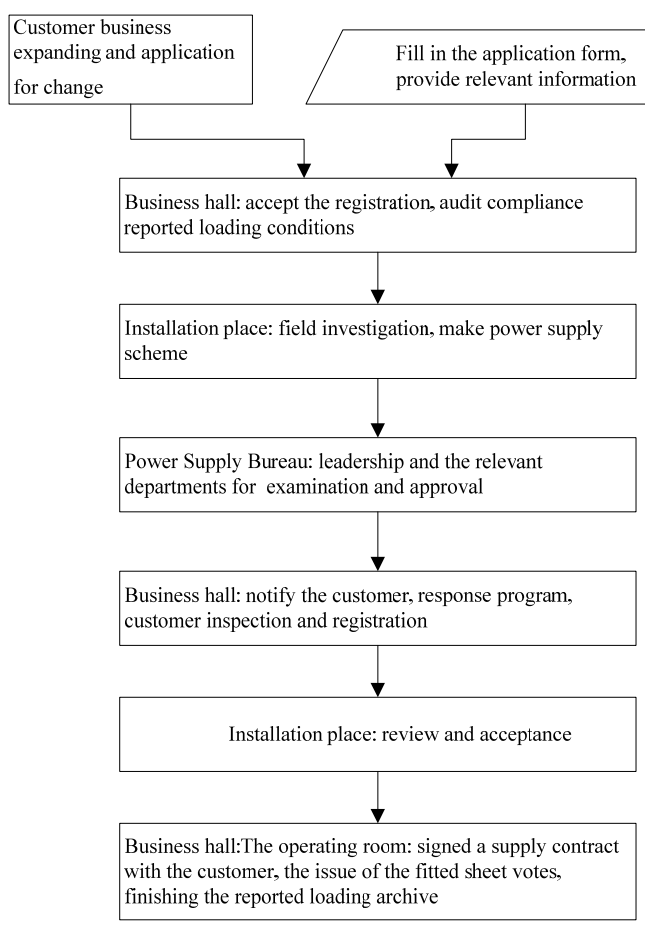

Figure 3. Business expanding the overall workflow

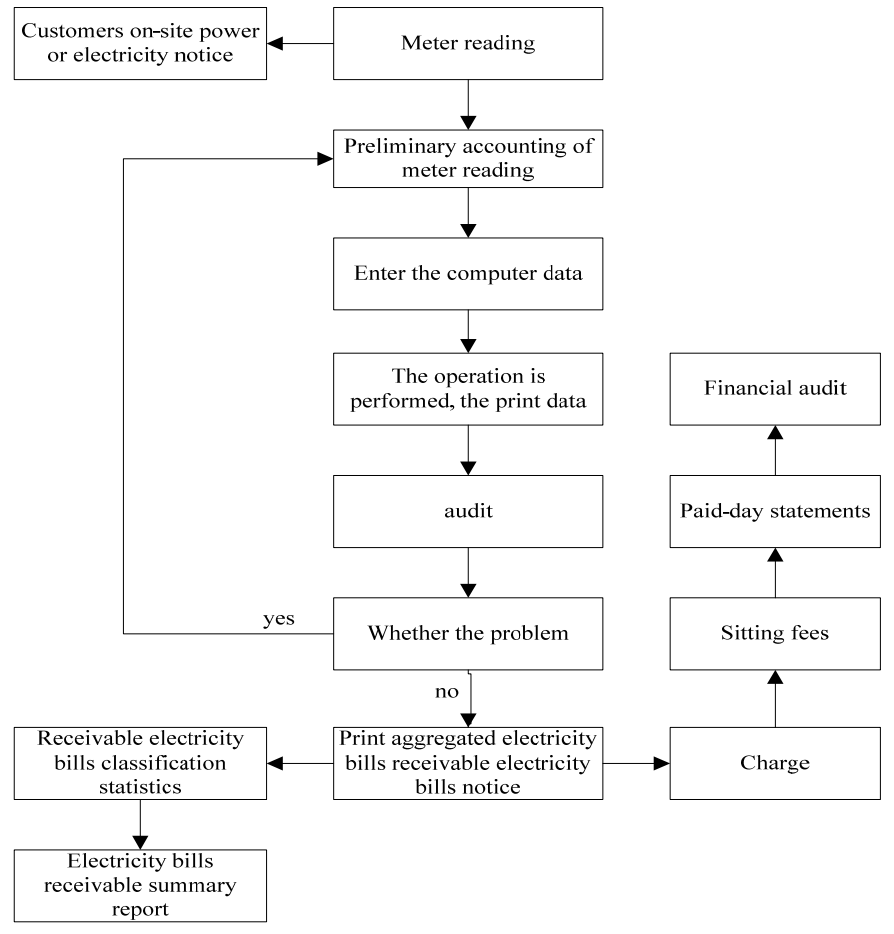

Figure 4. Copy, check, collection business process diagrams 


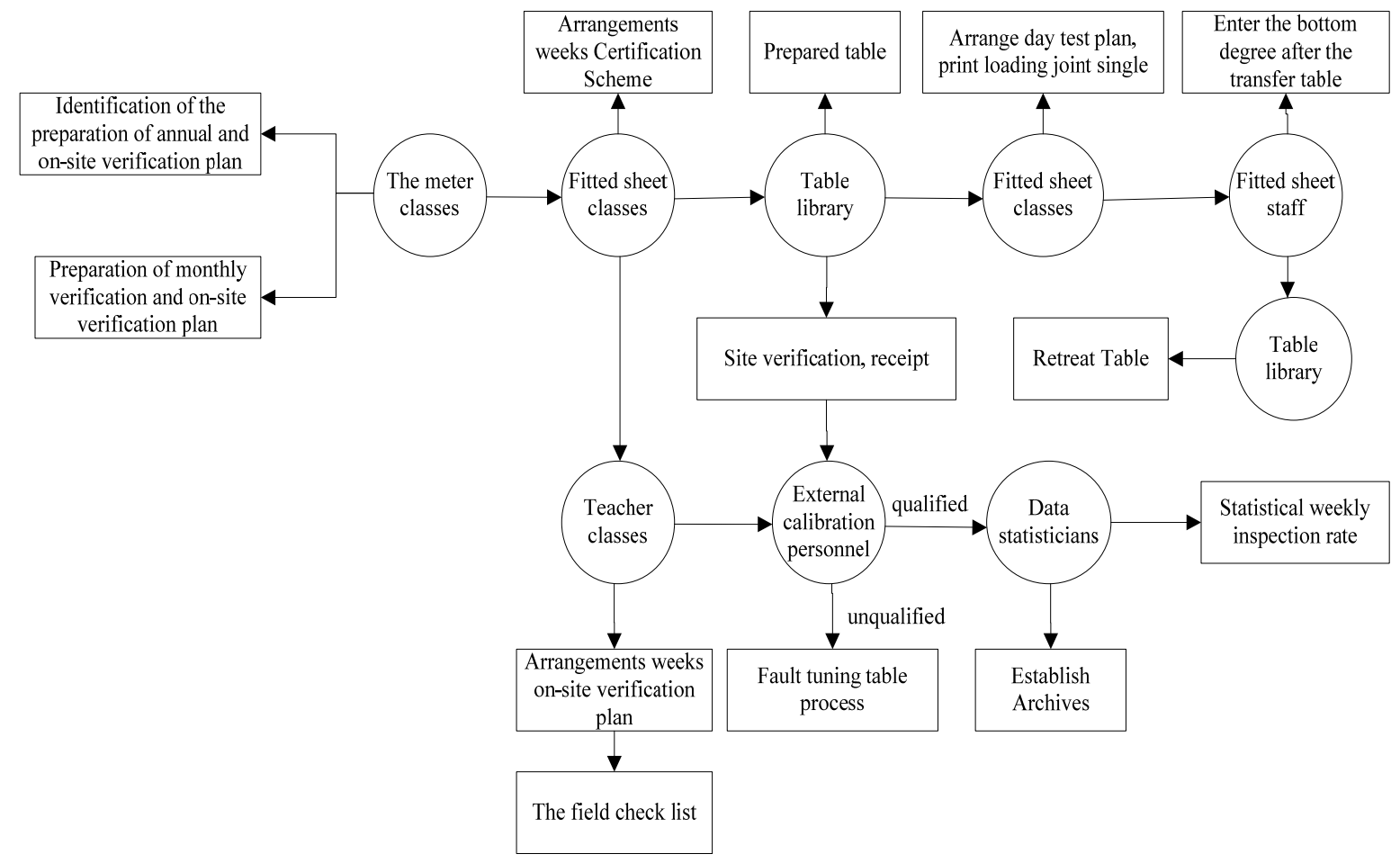

Figure 5. Regular test and field check flow chart

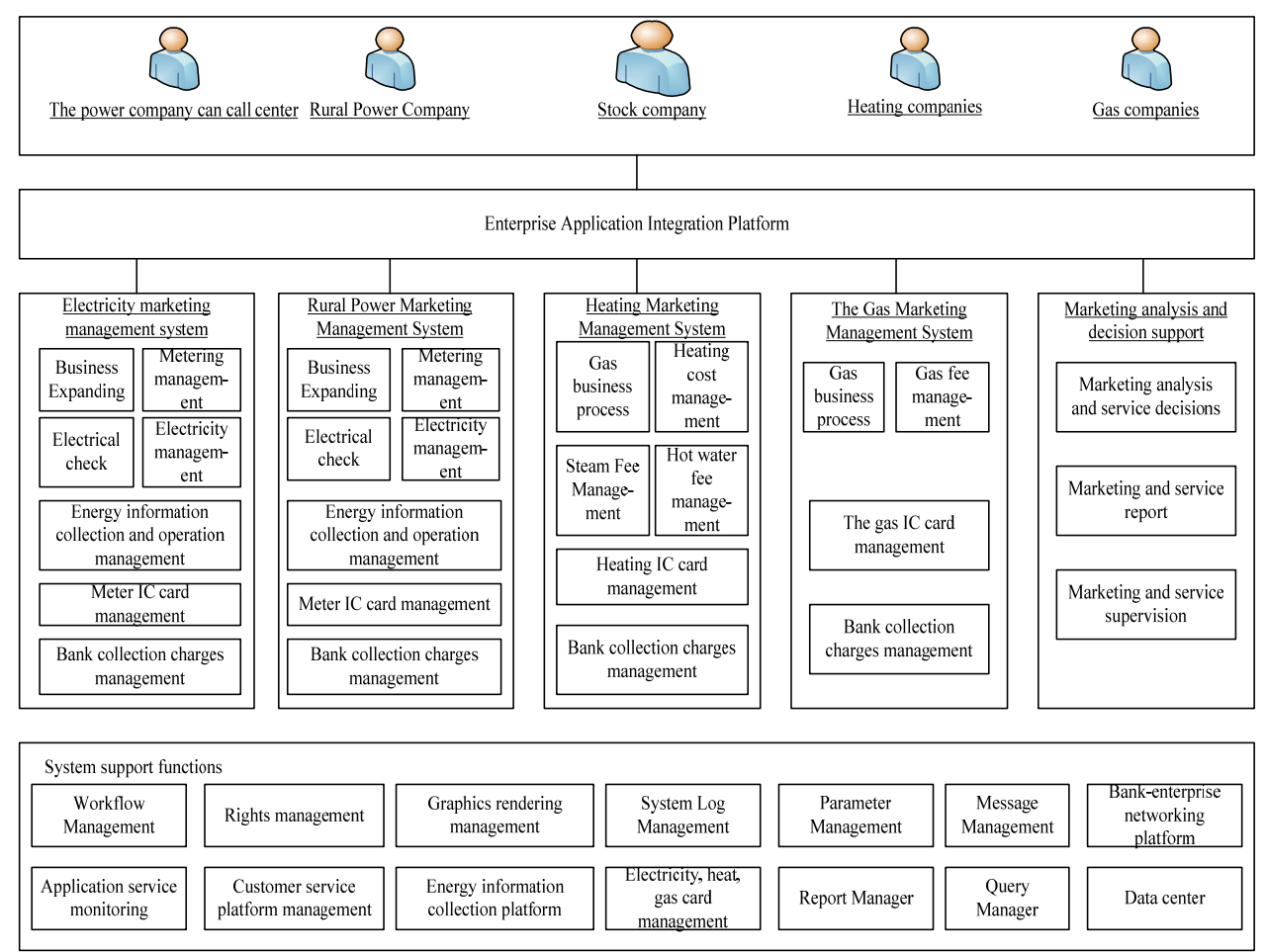

Figure 6. Enterprise Integration Application Platform 


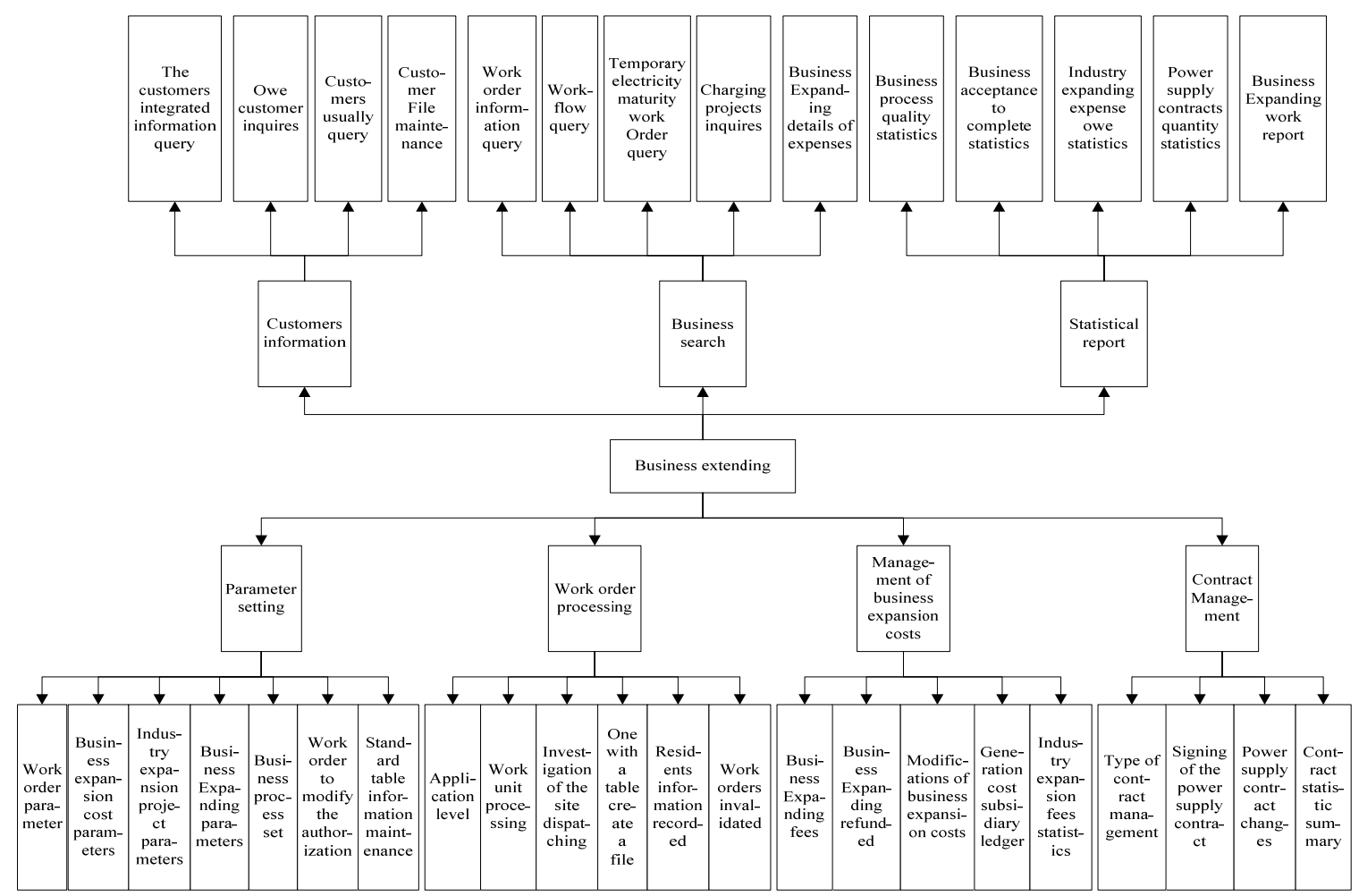

Figure7. Business expanding function module chart 